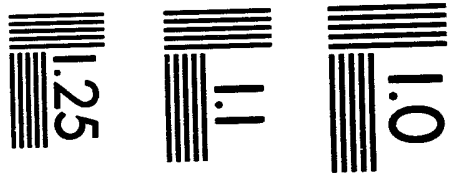

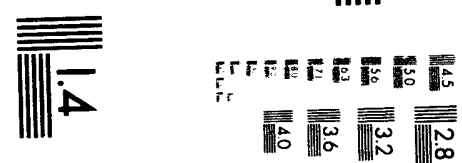

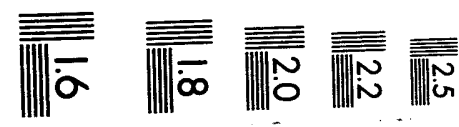



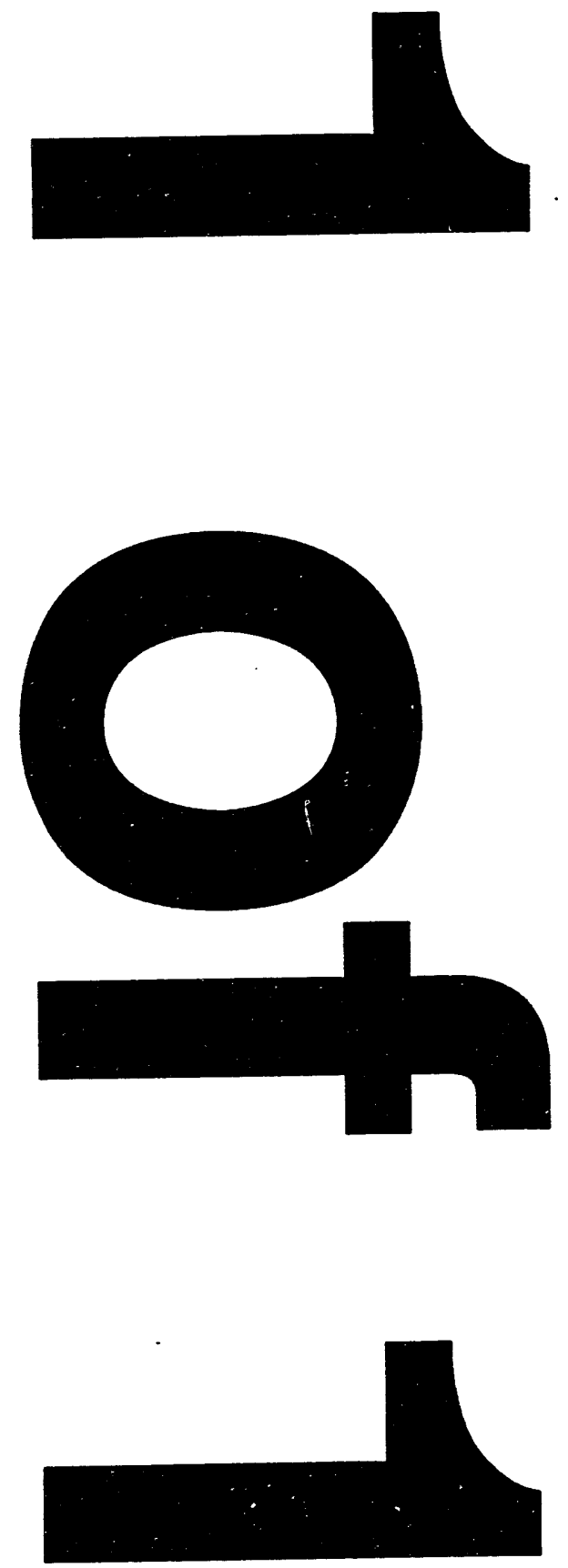


\title{
$\operatorname{Conf}-931054--8$
}

UCRL -JC-114998

PREPRINT

\section{Large-Area Conditioning of Optics for High-Power Laser Systems}

\author{
L. M. Sheehan, M. R. Kozlowski, \\ F. Rainer and M. C. Staggs
}

This paper was prepared for submittal to

The 1993 Boulder Damage Symposium

Boulder, Colorado

October 27-29, 1993

December 21, 1993

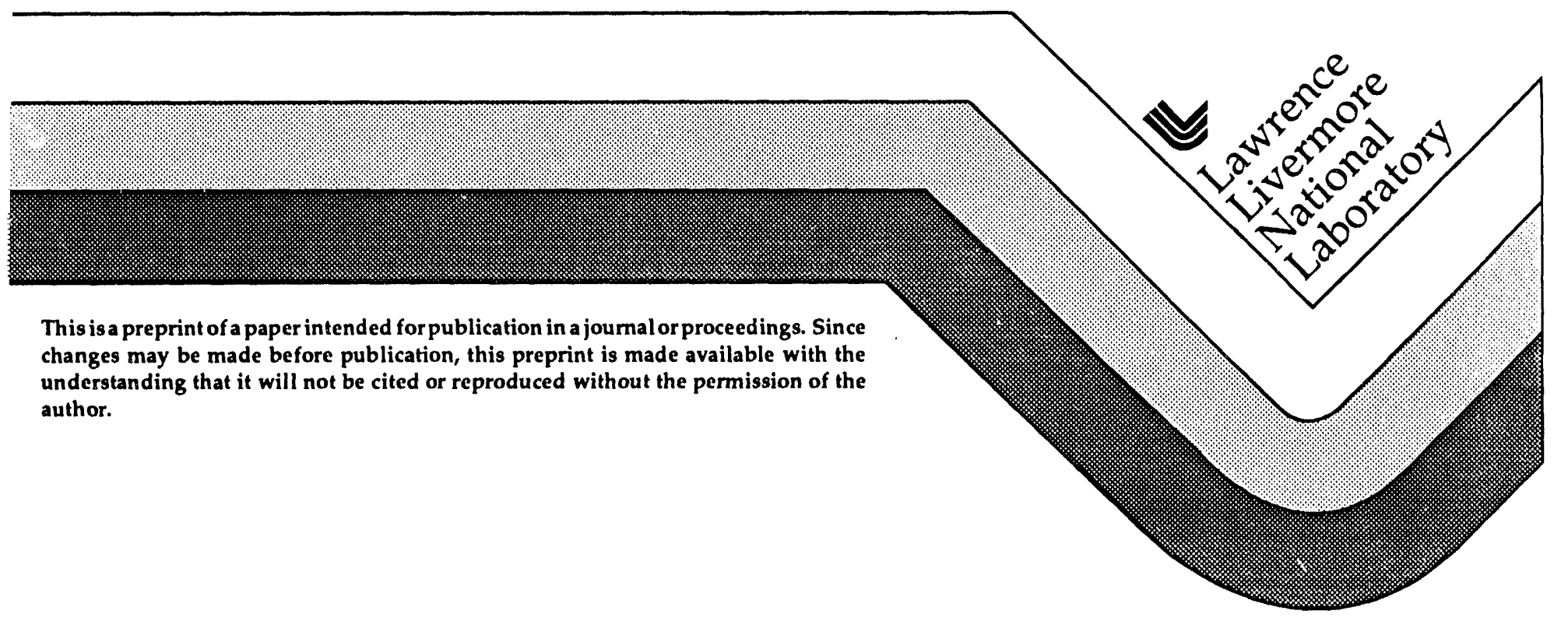




\section{DISCLAIMER}

This document was prepared as an account of work sponsored by an agency of the United States Government. Neither the United States Government nor the University of California nor any of their employees, makes any warranty, express or implied, or assumes any legal liability or responsibility for the accuracy, completeness, or usefulness of any information, apparatus, product, or process disclosed, or represents that its use would not infringe privately owned rights. Reference herein to any specific commercial products, process, or service by trade name, trademark, manufacturer, or otherwise, does not necessarily constitute or imply its endorsement, recommendation, or favoring by the United States Government or the University of Califomia. The views and opinions of authors expressed herein do not necessarily state or reflect those of the United States Government or the University of Califomia, and shall not be used for advertising or product endorsement purposes. 


\title{
Large-area conditioning of optics for high-power laser systems
}

\author{
Lynn Sheehan, Mark Kozlowski, Frank Rainer and Mike Staggs \\ University of California \\ Lawrence Livermore National Laboratory \\ P.O. Box 5508, L-484 \\ Livermore, California 94550-9900 \\ Telephone: (510) 422-3022 FAX: (510) 423-6506
}

\begin{abstract}
In order to reach the high fluence goals of the Beamlet laser at Lawrence Livermore National Laboratory (LLNL), the polarizers in the system must be laser conditioned to increase their damage thresholds. Research has shown that by using a six-step raster-conditioning program, the damage thresholds of the $\mathrm{HfO}_{2} / \mathrm{SiO}_{2}$ multilayer polarizer coatings can be increased to meet the Beamlet 3-ns design goal of $8 \mathrm{~J} / \mathrm{cm}^{2}$. Because of the large size of the polarizers $(73 \mathrm{~cm} \times 37 \mathrm{~cm} \times 9 \mathrm{~cm})$, a large-area conditioning facility was constructed capable of rastering a one-meter optic, weighing as much as 400 pounds, at any specified use angle. A large translational stage moves the optic in a raster pattern through a stationary, $10-\mathrm{Hz}$ rep-rated, 1064-nm beam with 10-ns pulses. A scatter measurement diagnostic allows on-the-fly evaluation of laser-induced damage and logs the coordinates of the damage. Laser energy is measured pulse-to-pulse in order to ensure stability during a scan. A small amount of minor coating damage does occur during the process, but the damage does not grow upon further irradiation. This damage causes only a small increase in total scatter compared to that due to the pre-existing defects, and would not influence the system performance.
\end{abstract}

\section{INTRODUCTION}

As the Inertial Confinement Fusion (ICF) program continues with the development of new laser designs capable of generating $1-2 \mathrm{MJ}$ of $0.35-\mu \mathrm{m}$ light, the damage thresholds of optical materials are being pushed to new limits. The best coatings available have laser damage thresholds that are only half of what is required for these systems. Research efforts are attempting to develop defect-free coatings in order to raise the threshold, but this solution is not available for the near term. It has been shown, however, that the damage thresholds of some multilayer optical coatings can be increased by factors of 2 to 3 as a result of preillumination at sub-threshold fluences. ${ }^{1-3}$ This pre-illumination, or conditioning, process will be used to meet the damage threshold goals of the Beamlet laser as well as the proposed $1-2 \mathrm{MJ}$ National Ignition Facility (NIF).

This paper presents the procedure and apparatus used to laser condition meter-scale $\mathrm{HfO}_{2} / \mathrm{SiO}_{2}$ multilayer polarizers which will be used in the Beamlet laser system. A study of different conditioning techniques, the effects of conditioning, and the determination of a practical process for conditioning large-area optics is presented.

\section{LASER CONDITIONING EXPERIMENTS}

There are four main types of illumination sequences which are used to determine unconditioned, $1: 1$ and $S: 1$, and conditioned, $\mathrm{N}: 1$ and $\mathrm{R}: 1$, damage thresholds. The 1:1 sequence irradiates a site with only one laser shot. The S:1 test irradiates a site with several hundred shots at an equal fluence. The $\mathrm{N}: 1$ test increments the fluence on a site in a step like manner, with a significant time period between each step. The R:1 test slowly increments the fluence, in a ramped manner, on a single site over several hundred shots. Both the $S: 1$ and $\mathrm{R}: 1$ tests are done with only $100 \mathrm{~ms}$ between each laser pulse. While the R:1 thresholds are generally higher than $\mathrm{N}: 1$ thresholds, the $\mathrm{N}: 1$ conditioning program is more practical for large optics. 


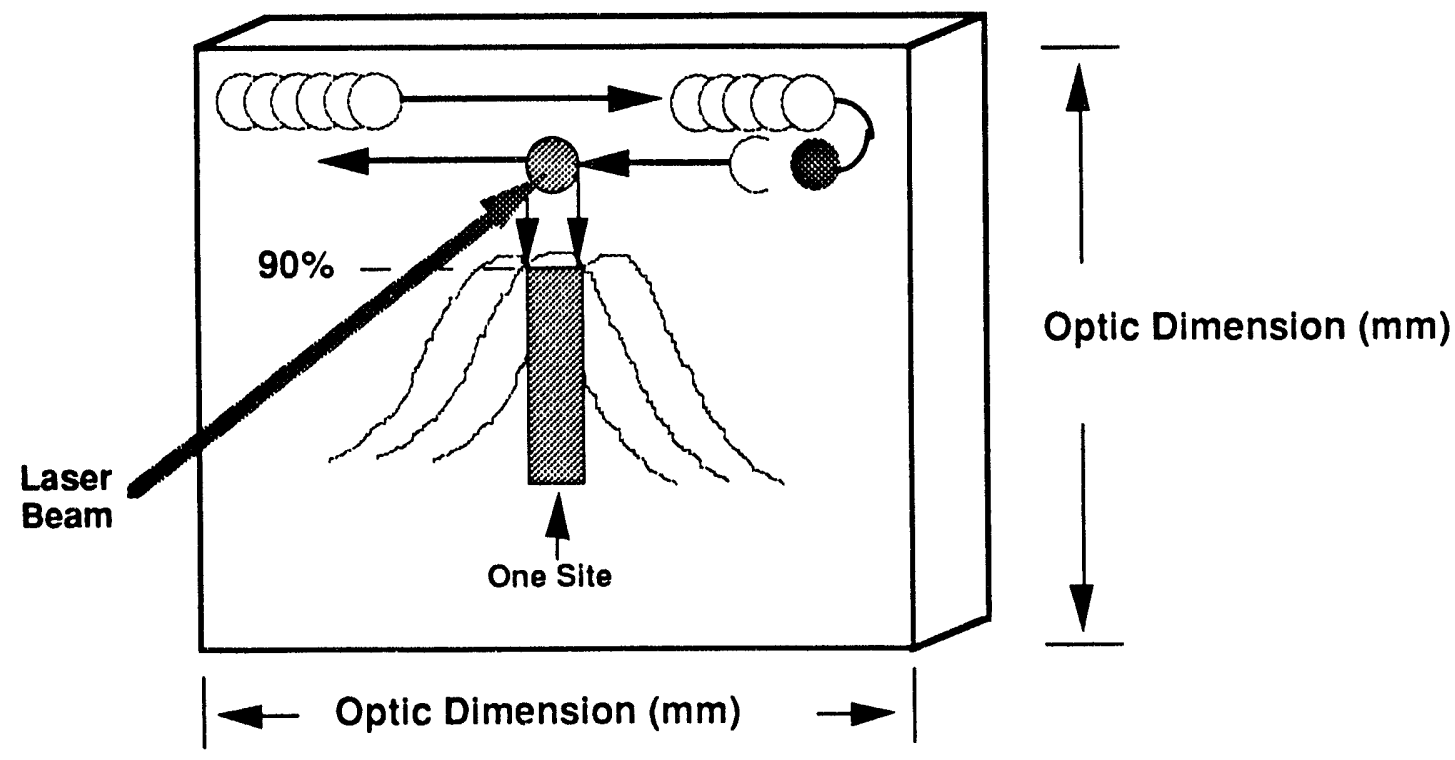

Fig. 1 Raster-conditioning involves scanning a small diameter beam over an area in a series of increasing fluence levels.

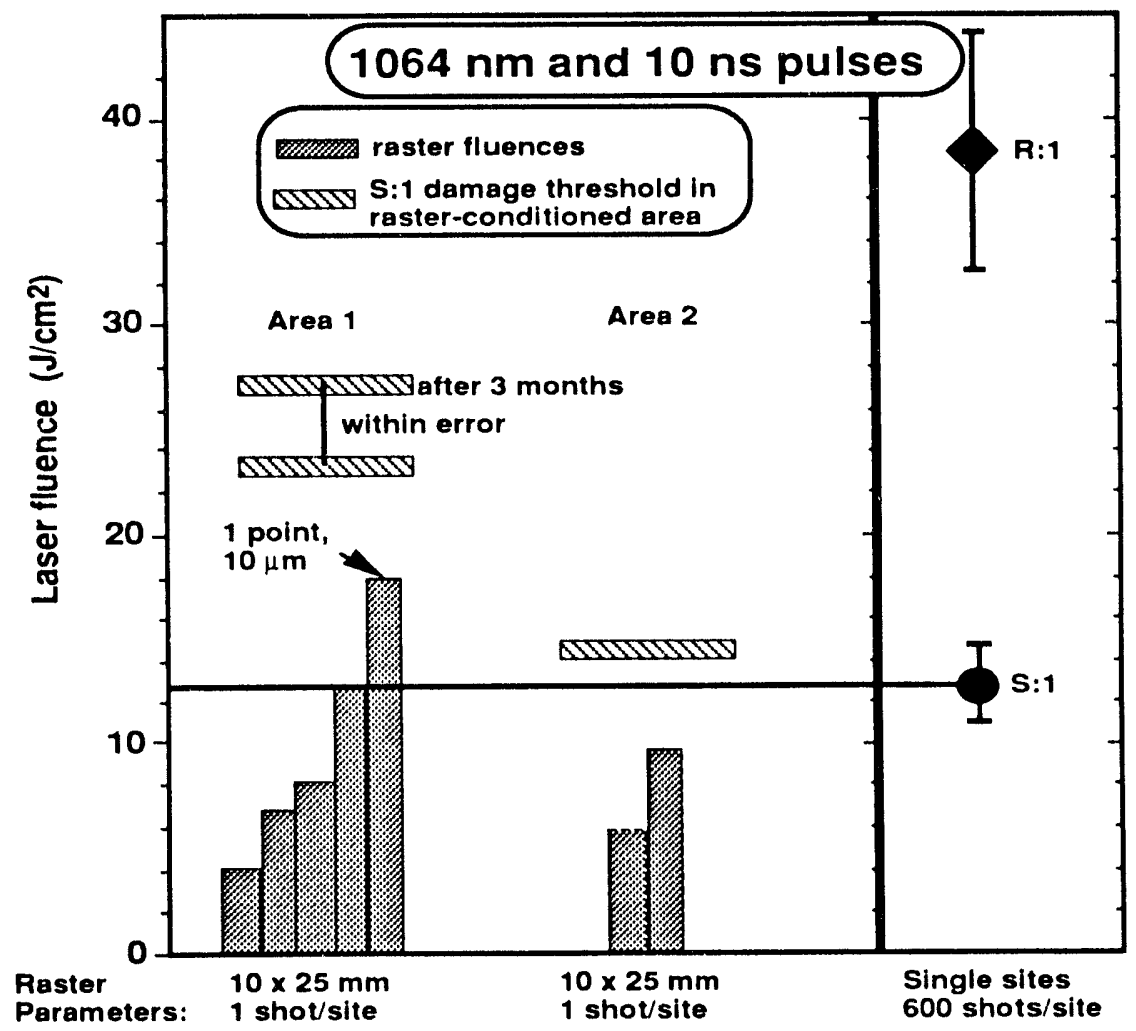

Fig. 2. Five-step raster-conditioning raised the $S: 1$ threshold by $1.8 \mathrm{x}$ but did not reach an $\mathrm{R}: 1$ conditioned value. The conditioning effect lasts for several months, but some minor damage did occur while conditioning. 
Early work in the area of conditioning showed that an $\mathrm{N}: 1$ process could be used to raise the damage thresholk of a 4 -cm-diameter area on a $\mathrm{HfO}_{2} / \mathrm{SiO}_{2}$ coating in-situ using the Nova laser at LLNL. ${ }^{3}$ More recent research: has concentrated on off-line conditioning techniques such as raster-condtioning. This technique involves scanning a small diameter beam over an area at a series of fluences with increasing magnitude (Fig. 1). This type of raster-step conditioning is most comparable to $\mathrm{N}: 1$ type conditioning where the fluence is incremented after each illumination. All of the conditioning results were achieved by illuminating the sample at the intended use angle and wavelength.

The results of raster- $\mathrm{ctep}$ conditioning tests on a $\mathrm{HfO}_{2} / \mathrm{SiO}_{2}$ polarizer coating are shown in Fig. 2. When an area of $10 \mathrm{~mm} \times 25 \mathrm{~mm}$ was rastered with five stepped fluences, the S:1 damage threshold increased by $1.8 \mathrm{x}$. When the same sized area was rastered with only two sub-threshold fluence steps, no conditioning effect was apparent. The coating's S:1 and R:1 damage thresholds are shown compared to the results of raster conditioning. The test showed that the raster-conditioned threshold was not as high as the R:1 threshold. It was also observed that the conditioning effect lasts for at least several months. However, some minor damage occurs during the conditioning process. This damage causes only a small increase in total scatter compared to that due to the pre-existing defects and does not influence the optical performance.

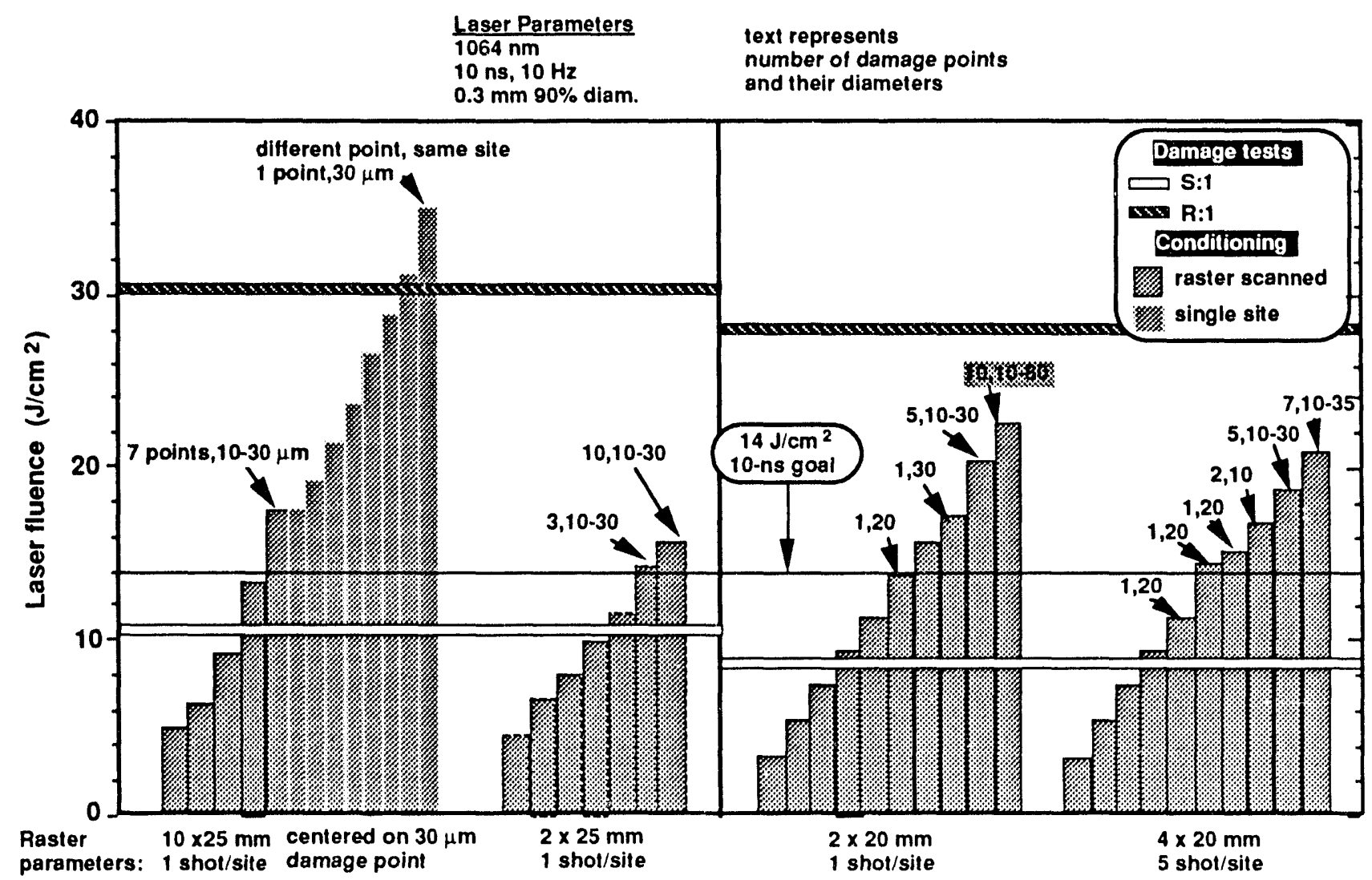

Fig. 3. Further raster-conditioning tests showed that damage that does occur is minor and does not grow upon further, higher-fluence illumination.

Figure 3 shows another series of tests which were used to better determine the amount of damage that might occur during conditioning. Four separate tests are shown, differentiated by the area rastered and the number of shots per-site used. Different fluence steps were also used. During all four tests, a small amount of minor damage began to appear at the fluence levels which were above the $S: 1$ threshold of the sample. In the first test, the beam was centered on one of the 30- $\mu \mathrm{m}$ damage points, and the fluence was stepped up. The original 
30- $\mu \mathrm{m}$ damage point did not grow, but a second damage point appeared at $35 \mathrm{~J} / \mathrm{cm}^{2}$. These tests showed that the damage that does occur is minor, and does nrt grow upon further, higher fluence, illumination. Experience with the Nova system and results of beam propagation modeling suggests that damage points less than $100-200 \mu \mathrm{m}$ in diameter do not influence the system.

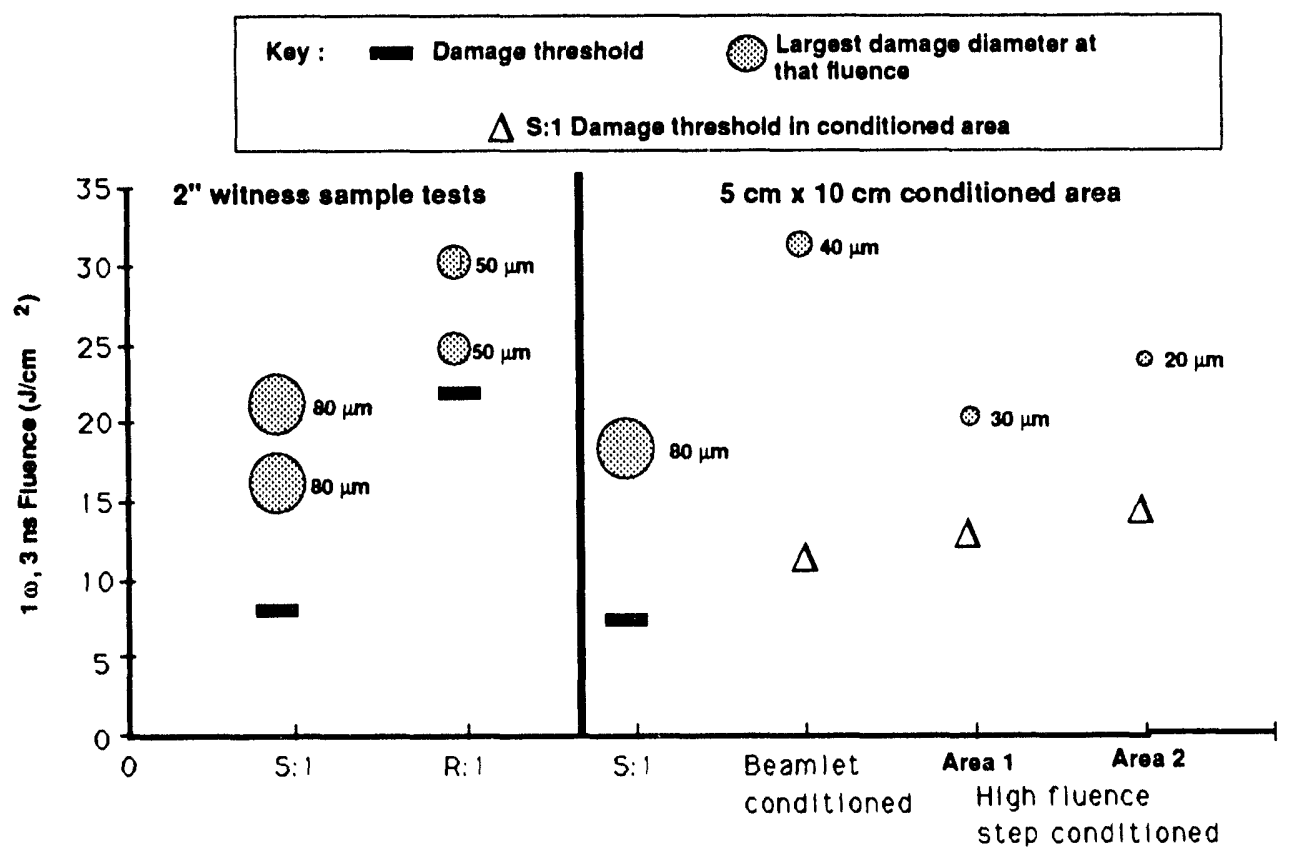

Fig. 4 The conditioning process reduced the severity of laser damage at high fluences by $1.6 \mathrm{x}-4.0 \mathrm{x}$

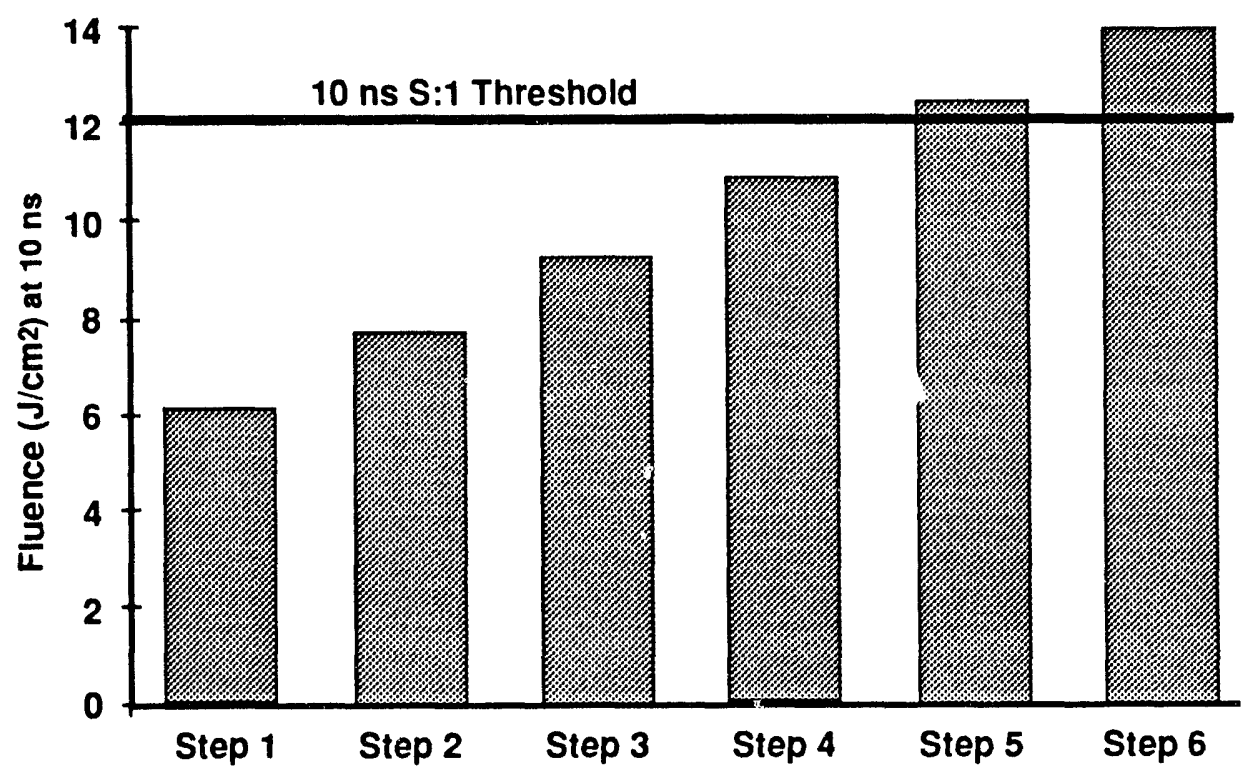

Fig. 5 Six-step raster-conditioning procedure is used to condition Beamlet polarizers.

The conditioning process was also shown to reduce the severity of laser damage at high fluences by as much as $1.6 x-4.0 x$, as well as increasing the $S: 1$ threshold. Figure 4 shows the results of tests on a witness sample 
as well as on a $5 \mathrm{~cm} \times 10 \mathrm{~cm}$ conditioned area. In both cases, when some type of conditioning was applied to the coating, either R:1 or raster-step conditioning, the size of the largest damage points observed at a given fluence decreased significantly.

This research lead to the development of a six-step raster-step-conditioning procedure, shown in Fig. 5, that was used to condition the Beamlet polarizers. The first fluence is equal to one-half the S:1 threshold as determined on witness samples. The six steps are then equally spaced up to a final level which exceeds the Beamlet fluence requirements for that optic by a $15 \%$ safety margin.

The procedure given in Fig. 5 was first tested on a witness sample from the Beamlet polarizer production run. As shown in Fig. 6, the S: 1 threshold was $7.1 \mathrm{~J} / \mathrm{cm}^{2}$. An area of $5 \mathrm{~cm} \times 10 \mathrm{~cm}$ was conditioned following the outlined procedure, ana the $S: 1$ damage threshold within the conditioned area was $11.5 \mathrm{~J} / \mathrm{cm}^{2}$, an increase in threshold of $1.6 x$.

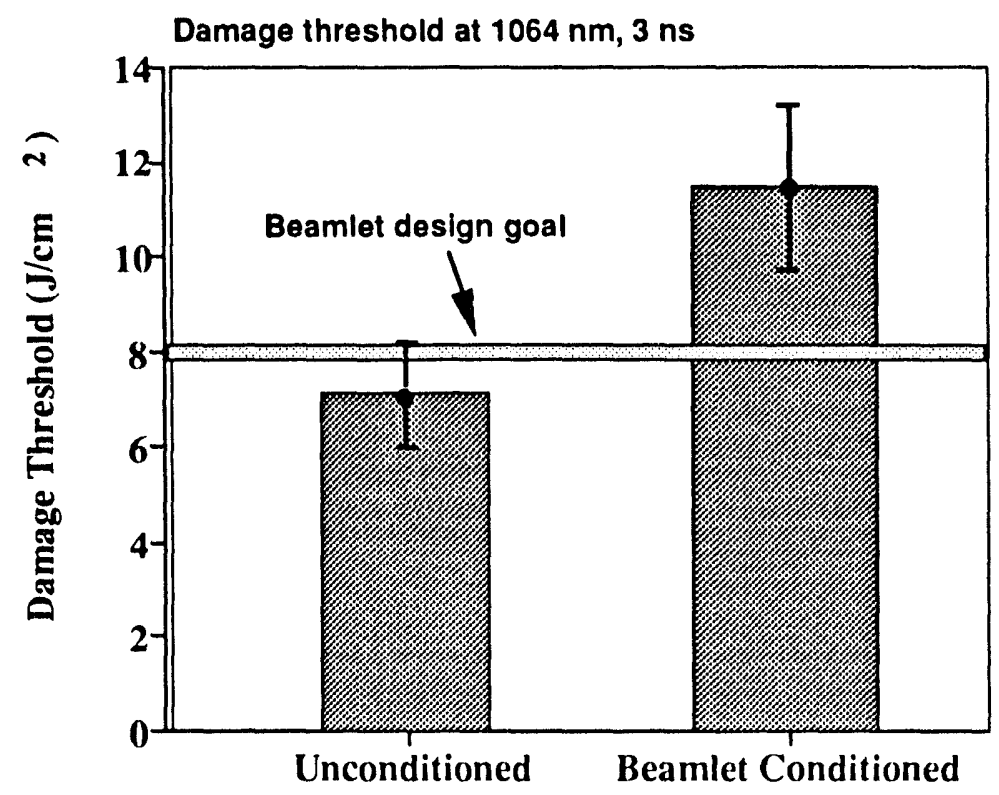

Fig. 6 By applying the raster-conditioning technique, the damage threshold of the polarizer increased by $1.6 x$.

\section{LARGE-AREA CONDITIONING SYSTEM}

Figure 7 shows the system constructed to do the large-area conditioning. The laser used for conditioning is a 1064-nm, 1.4-J, Nd:YAG, operating at a 10-Hz rep-rate with a 10-ns pulsewidth. A variable attenuator allows the laser energy to change from nearly zero up to the maximum available. A telescope with an effective focal length of 10 meters is used to focus the beam down to a $3-\mathrm{mm}, 1 / \mathrm{e}^{2}$ beam diameter. Laser fluence is measured in an equivalent sample plane using a beam profiler and a joulemeter. The laser pulsewidth is also monitored. The optic is placed on a translational stage, capable of moving a meter-scale optic weighing up to 400 pounds. The entire translation table can be rotated \pm 90 degrees, so that the coating can be conditioned at its use angle. This is important for interference coatings where the laser-induced electric fields are influenced by illumination angle. The stage has better than $100 \mu \mathrm{m}$ of repeatability. The entire translation and damage detection system is covered by a class 100 cleanroom.

The coating is monitored for damage using a scatter detection system similar to what others have implemented. ${ }^{4-6}$ This scatter system measures the intensity of scattered light just before and just after the 


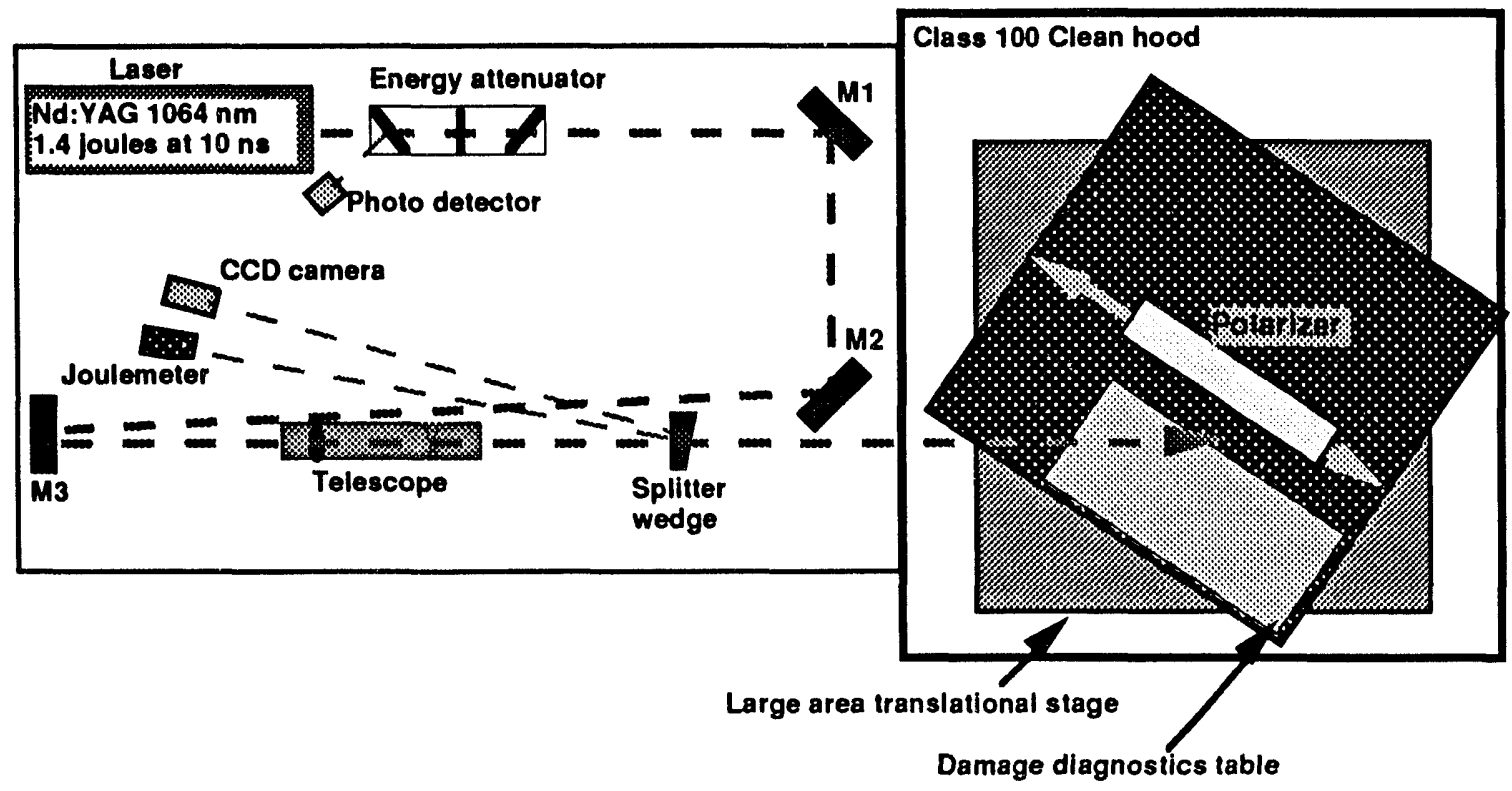

Fig. 7. Large-area conditioning facility layout.

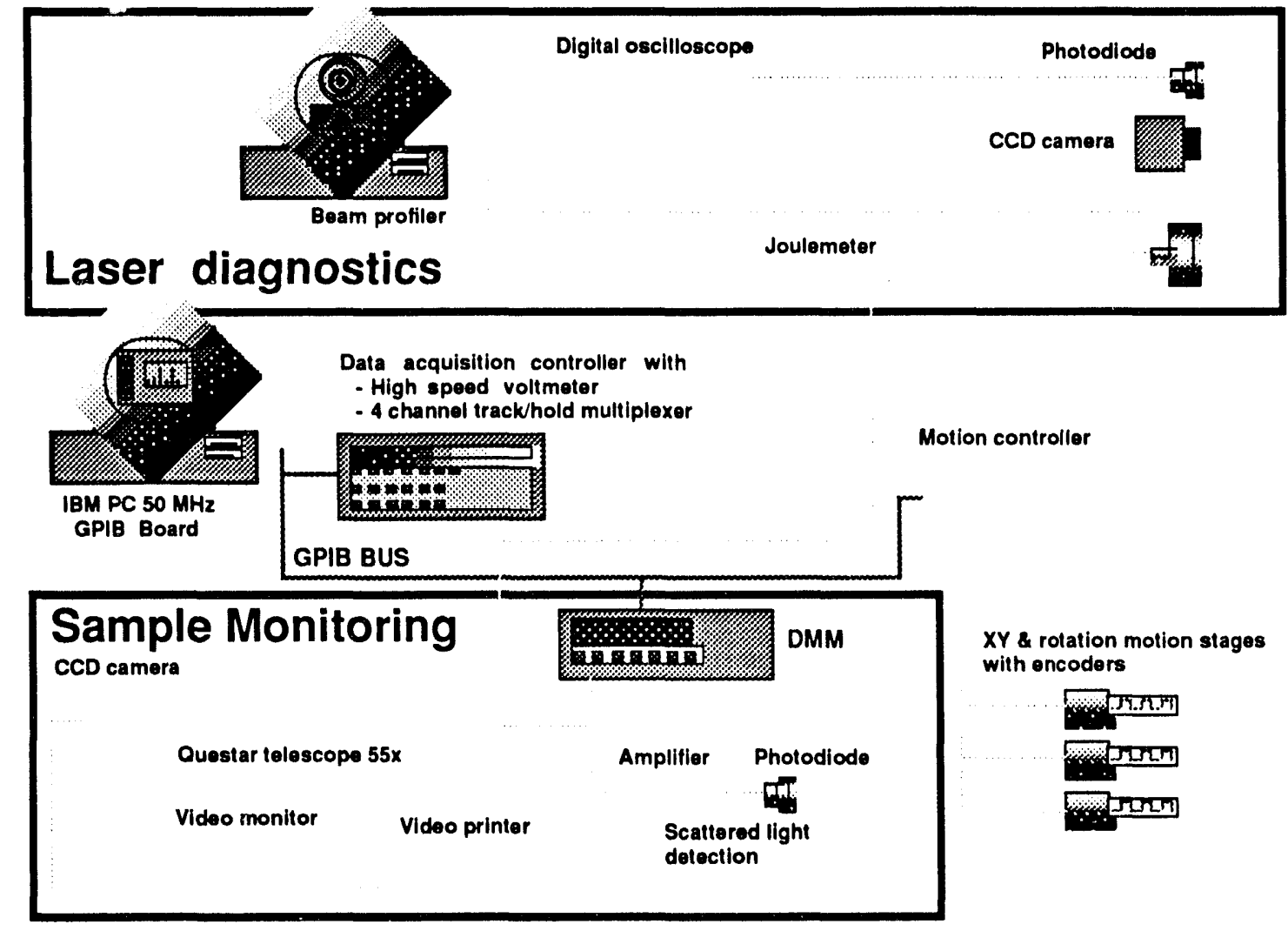

Fig. 8. Schematic of conditioning facility control and diagnostic systems. 
laser fires. By subtracting the before measurement from the after, scatter changes caused by laser damage or by surface cleaning can be detected. The scatter-detection system has a design spatial resolution of 20 $\mu \mathrm{m}$. A Questar telescope with magnification of 50x is also used to monitor the optic surface and to record plasma emissions associated with laser damage of the coating.

The interaction of all of the system elements is shown in Fig. 8. By using all of the diagnostics available, the system can operate virtually unattended. The software, which controls the process, compares laser energy and change-in-scatter $(\Delta S)$ readings to user-programmable limits. If a limit for either is exceeded, the xy coordinate and the diagnostic level for the event is recorded. If a critical limit is exceeded, the system halts all operation and warns the operator. For the laser energy, the non-critical and critical limits were $\pm 15 \%$ of the set energy. For the $\Delta \mathrm{S}$ limits, non-critical limits were set for signals representing approximately 20to 70- $\mu \mathrm{m}$-damage diameters and critical limits were set to levels representing damage diameters greater than approximately $70 \mu \mathrm{m}$, based on additional calibration experiments.

\section{CONDITIONING OF BEAMLET POLARIZERS}

A Beamlet polarizer with a clear aperture of $73.4 \mathrm{~cm} \times 37.0 \mathrm{~cm}$ was raster conditioned using the six-step program shown in Fig. 5. Each scan took approximately 15 hours. During each conditioning scan the scatter diagnostic recorded 500-900 non-critical $\Delta S$ sites. This represents $0.15 \%-0.26 \%$ of the 340,000 total sites illuminated. The number of positive and negative $\Delta S$ values were comparable for scans 1 through 5 , and negative signals made up approximately half the data points. During scan 6 , the first above-S:1-threshold scan, approximately $30 \%$ more sites were detected. This is consistent with earlier findings in which damage

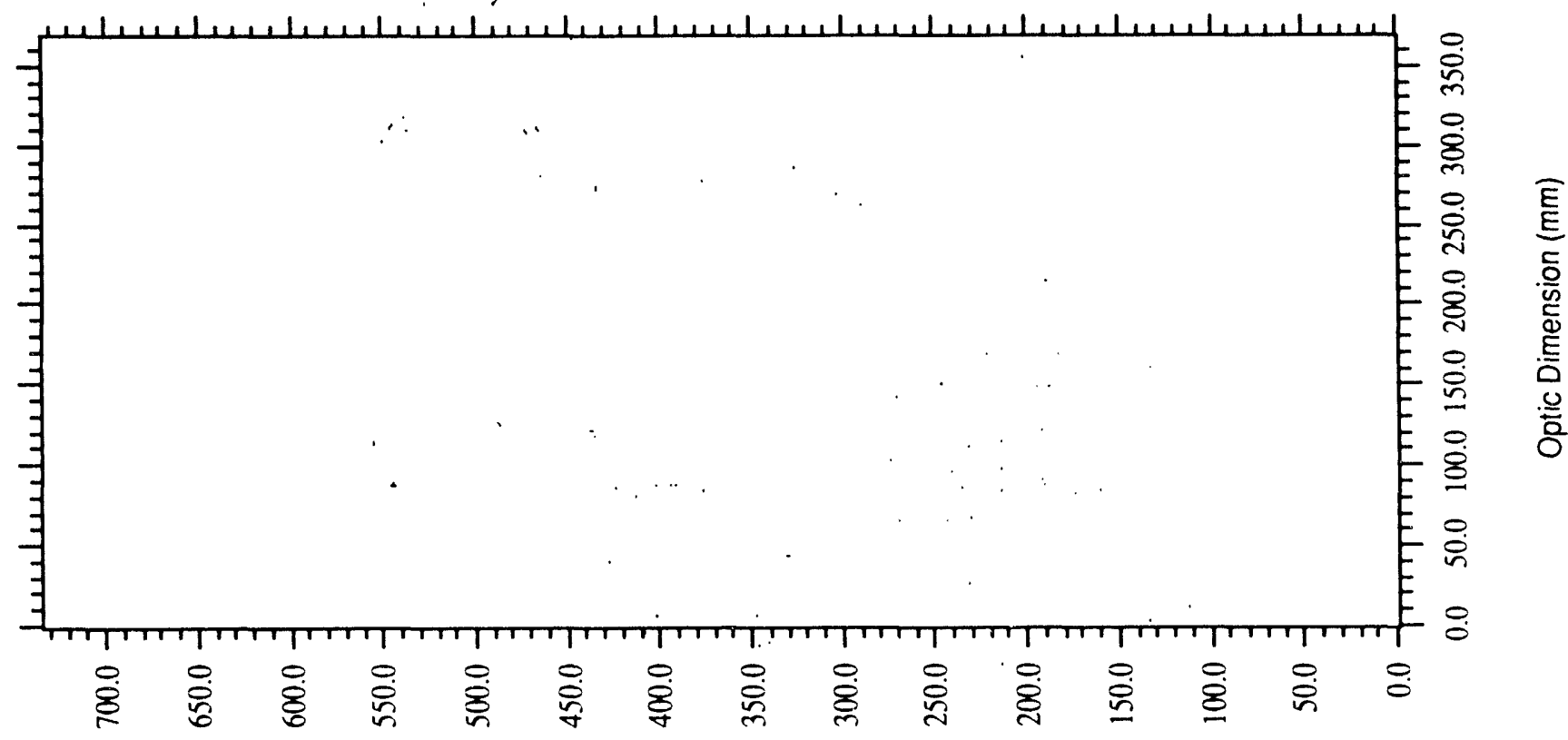

Optic Dimension (mm)

Fig. 9. Map of the recorded $\Delta \mathrm{S}$ signals for scan 2 with $\Delta \mathrm{S}$ signal resolution set for $\sim 20 \mu \mathrm{m}$ damage sites.

becomes more prominent at above-threshold conditioning steps. A map of the xy coordinates of recorded $\Delta \mathrm{S}$ signals for scan 2 is shown in Fig. 9. This scan is representative of the appearance of scans 1 through 5. There appear to be specific areas where a conglomeration of $\Delta \mathrm{S}$ sites are found, and other areas where there are none. Figure 10 shows the map of the $\Delta S$ sites recorded during scan 6 . Not only did the number of detected sites increase by $30 \%$, but they were more widely distributed across the optic. 


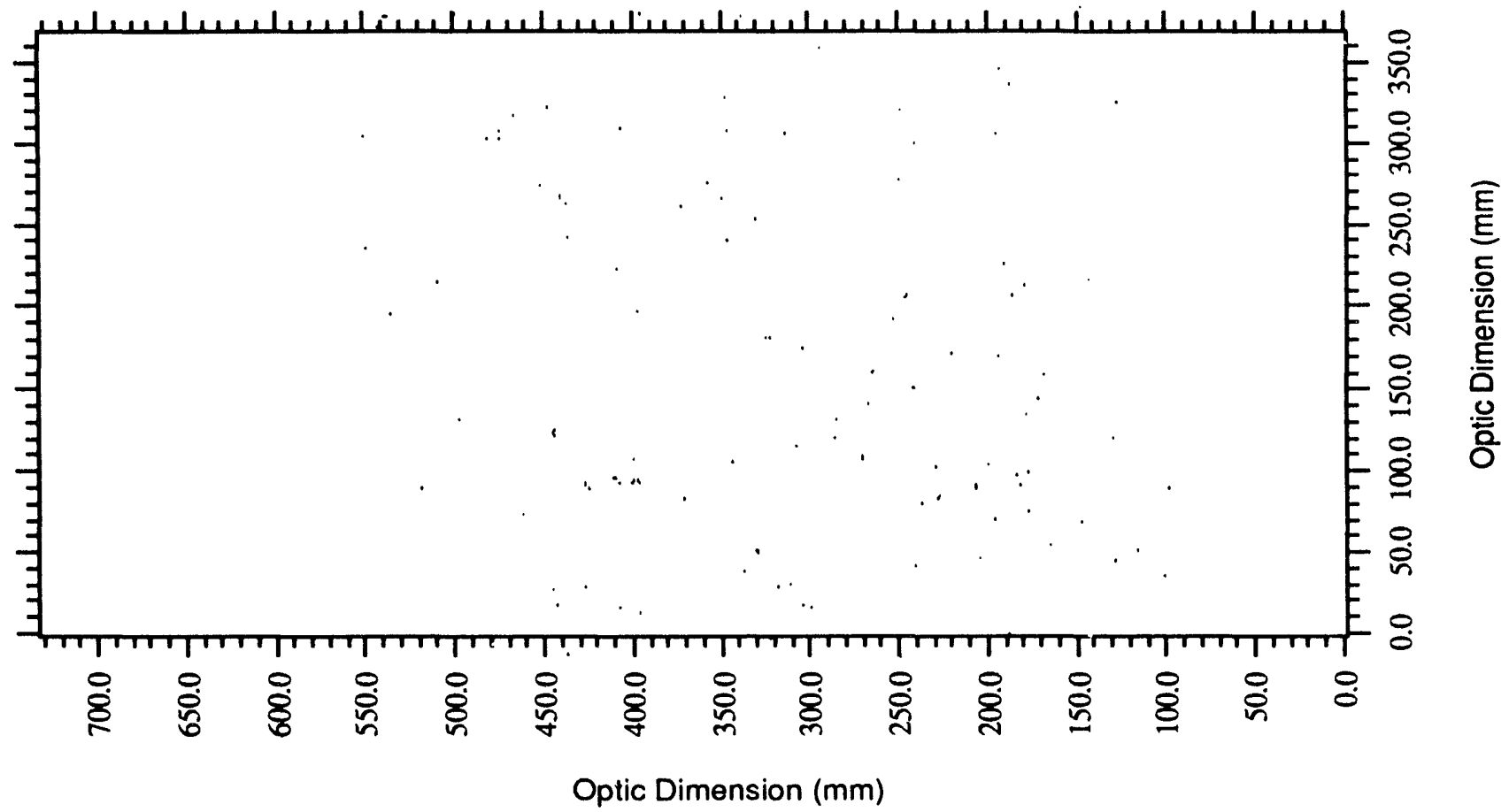

Fig 10 Map of the recorded $\Delta S$ sites for scan 6 with $\Delta S$ signal resolution set for $\sim 20 \mu \mathrm{m}$ damag sites.

Damage diameters $>\mathbf{2 0} \mu \mathrm{m}$

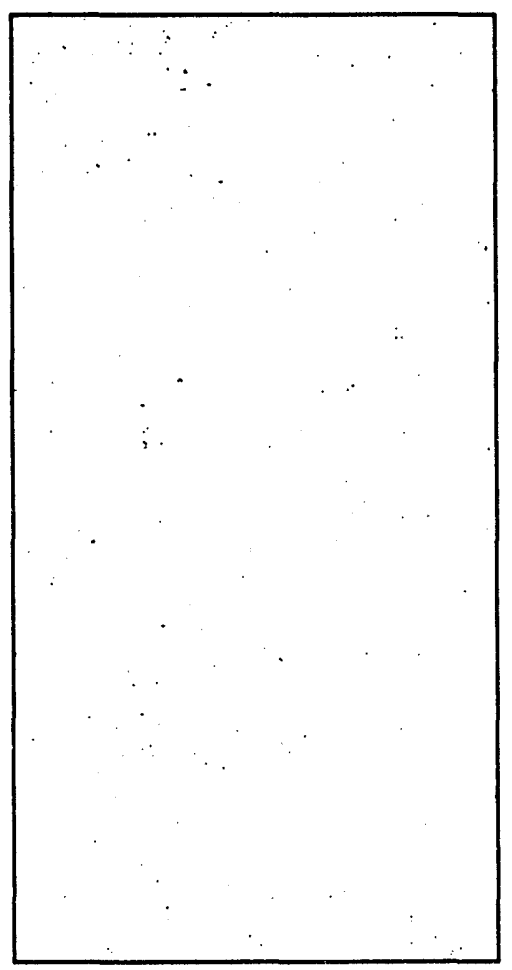

Damage diameters $>50 \mu \mathrm{m}$

Damage diameters $>70 \mu \mathrm{m}$

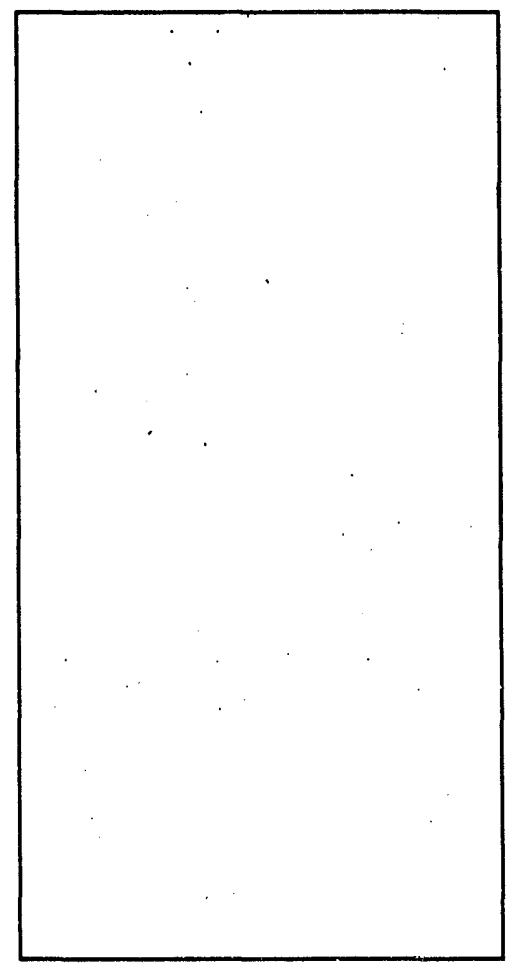

\section{Damage dlameters $>70 \mu \mathrm{m}$}

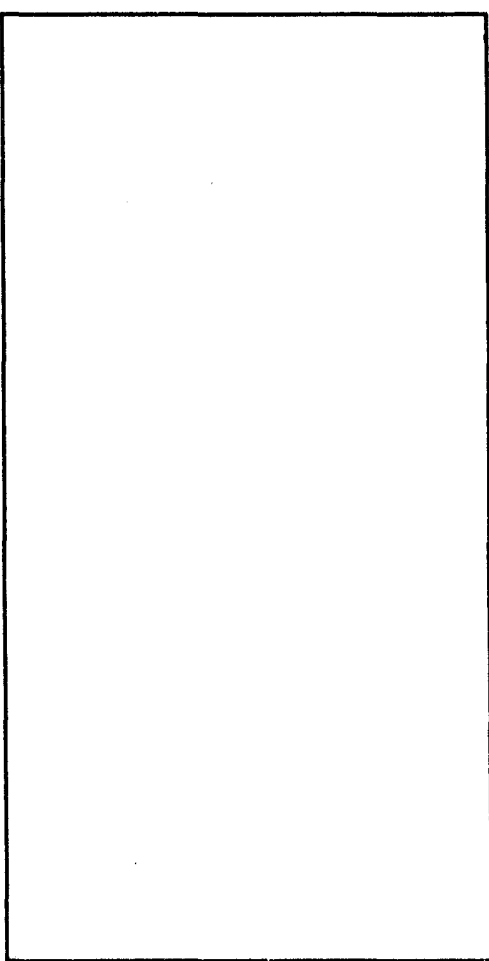

Fig $11 \Delta \mathrm{S}$ maps for scan 6 with $\Delta \mathrm{S}$ signal cutoff set for damage diameters greater than $20 \mu \mathrm{m}$, $50 \mu \mathrm{m}$, and $70 \mu \mathrm{m}$. No signals indicating damage diameters greater than $80 \mu \mathrm{m}$. 
As mentioned before, the small damage diameters do not influence the optical performance. As the lower limit of diameters recorded increases, the density of points on the map decreases significantly. Figure 11 shows the $\Delta \mathrm{S}$ map for scan 6 as the $\Delta \mathrm{S}$ cutoff is changed to only include data representing damage diameters $>20 \mu \mathrm{m},>50 \mu \mathrm{m}$, and $>70 \mu \mathrm{m}$. Damage diameters that exceed $80 \mu \mathrm{m}$ were not detected in any of the six scans.

Scans $1-5$ had very similar $\Delta S$ maps, which was not expected since the same sites should not damage multiple times. It was found that a map similar to scans 1-5 could be generated without illuminating the sample with the conditioning beam, meaning that the scatter detection system was recording damage where none had occurred. The problem has since been narrowed down to electronic noise and a motion-relative scatter error. The electronic noise is influenced by acoustic signal generation by the laser which couples into the scatter

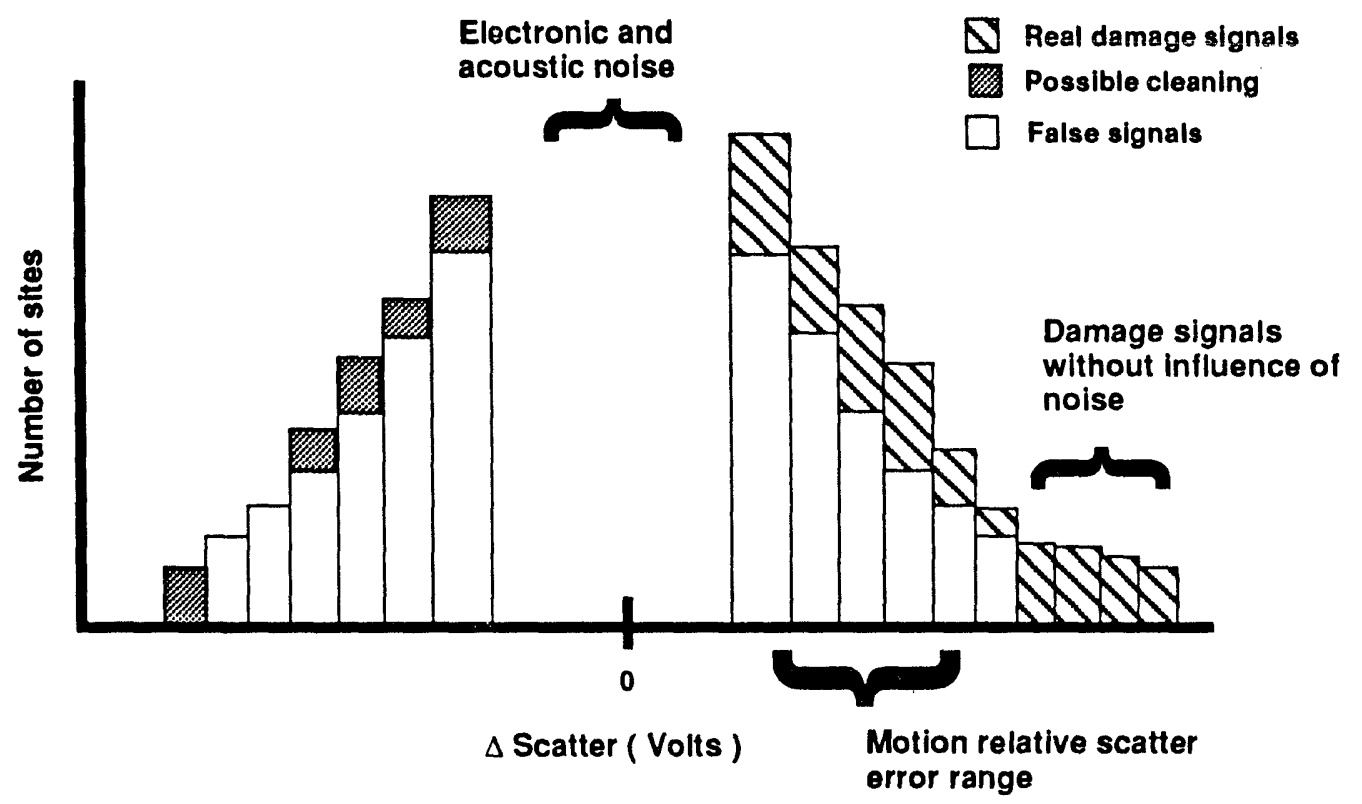

Fig 12 The recorded $\Delta S$ values were affected by noise as shown.

The contribution is likely significant, possibly as much as $50 \%$, which means that $<0.1 \%$ of the sites recorded represent damage.

detection system. The motion-relative scatter error is due to high-scatter sources on the optic which can move into, or out of, the field of view of the diagnostic between the before- and after-scatter measurements. These two errors contribute to a large number of the 500-900 sites detected. Figure 12 shows a schematic histogram plot of $\Delta S$ data and indicates the relative contributions of the various $\Delta S$ signal sources. This means that the number of $\Delta S$ signals representing damage is actually much less than $0.15 \%-0.26 \%$ of the total sites which showed a $\Delta S$ signal.

\section{CONCLUSIONS}

Laser conditioning of meter-sized optics is possible and has been demonstrated on the polarizers for the Beamlet laser system. By applying a raster-step conditioning procedure to the polarizer coatings, the S:1 damage threshold increased by $1.6 x$, and the severity of damage that might occur at higher fluences was reduced by $1.6 \mathrm{x}$ to $4.0 \mathrm{x}$. The process does induce minor damage $(<80 \mu \mathrm{m})$ to the coating, but optical performance is not affected. Scatter measurements made during conditioning indicated that minor damage was measured on $<0.1 \%$ of the $340,000,1-\mathrm{mm}$-diameter sites illuminated. 


\section{ACKNOWLEDGEMENTS}

Work was done under the auspices of the U.S. Department of Energy by Lawrence Livermore National Laboratory under contract numier W-7405-ENG-48.

\section{REFERENCES}

1. C. Wolfe, M. R. Kozlowski, J. H. Campbell, F. Rainer, A. J. Morgan, and R. P. Gonzales, "Laser Conditioning of Optical Thin Films", Laser Induce Damage in Optical Materials; 1989, NBS Spec. Pub. 801, 360, 1990.

2. M. Staggs, M. Baloch, M. Kozlowski, W. Siekhaus, "In-Situ Atomic Force Microscopy of LaserConditioned and Laser-Damaged $\mathrm{HfO}_{2} / \mathrm{SiO}_{2}$ Dielectric Mirror Coatings", Laser Induced Damage in Optical Materials: 1991, SPIE 1624, 375, 1992.

3. M. R. Kozlowski, C. R. Wolfe, M. C. Staggs and J. H. Campbell, "Large Area Laser Conditioning of Dielectric Thin Film Mirrors", Laser Induced Damage in Optical Coatings; 1989, NBS Spec. Pub. 801, 376, 1990.

4. S. Seitel, M. Babb, "Laser-Induced Damage Detection and Assessment by Enhanced Surface Scattering", Laser Induced Damage in Optical Coatings; 1986, NBS Spec. Pub. 752, 83, 1987.

5. J. Franck, S. C. Seitel, V. A. Hodgkin, W. N. Faith and J. O. Porteus, “Automated Pulsed Testing Using a Scatter-Probe Damage Monitor", Lascr Induced Damage in Optical Coatings; 1984, NBS Spec. Pub. 727, 71, 1985.

6. M. Moran, R. Kuo, and C. Marrs, “Scatter Intensity Mapping of Laser-Illuminated Coating Defects", Laser Induced Damage in Optical Coatings; 1986, NBS Spec. Pub. 752, 235, 1987. 


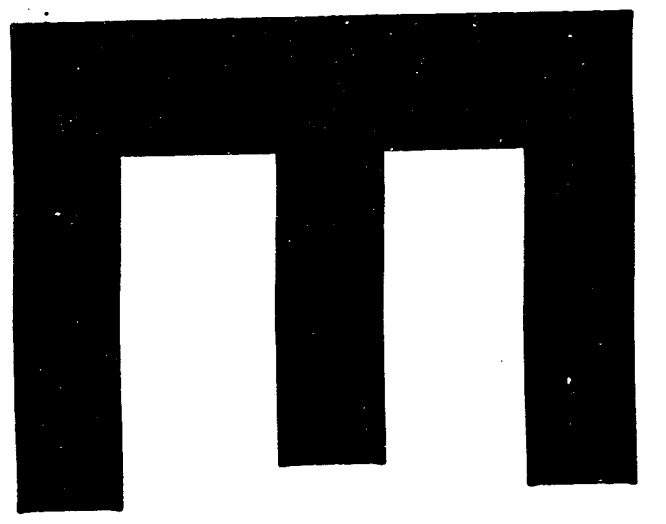

$\omega$
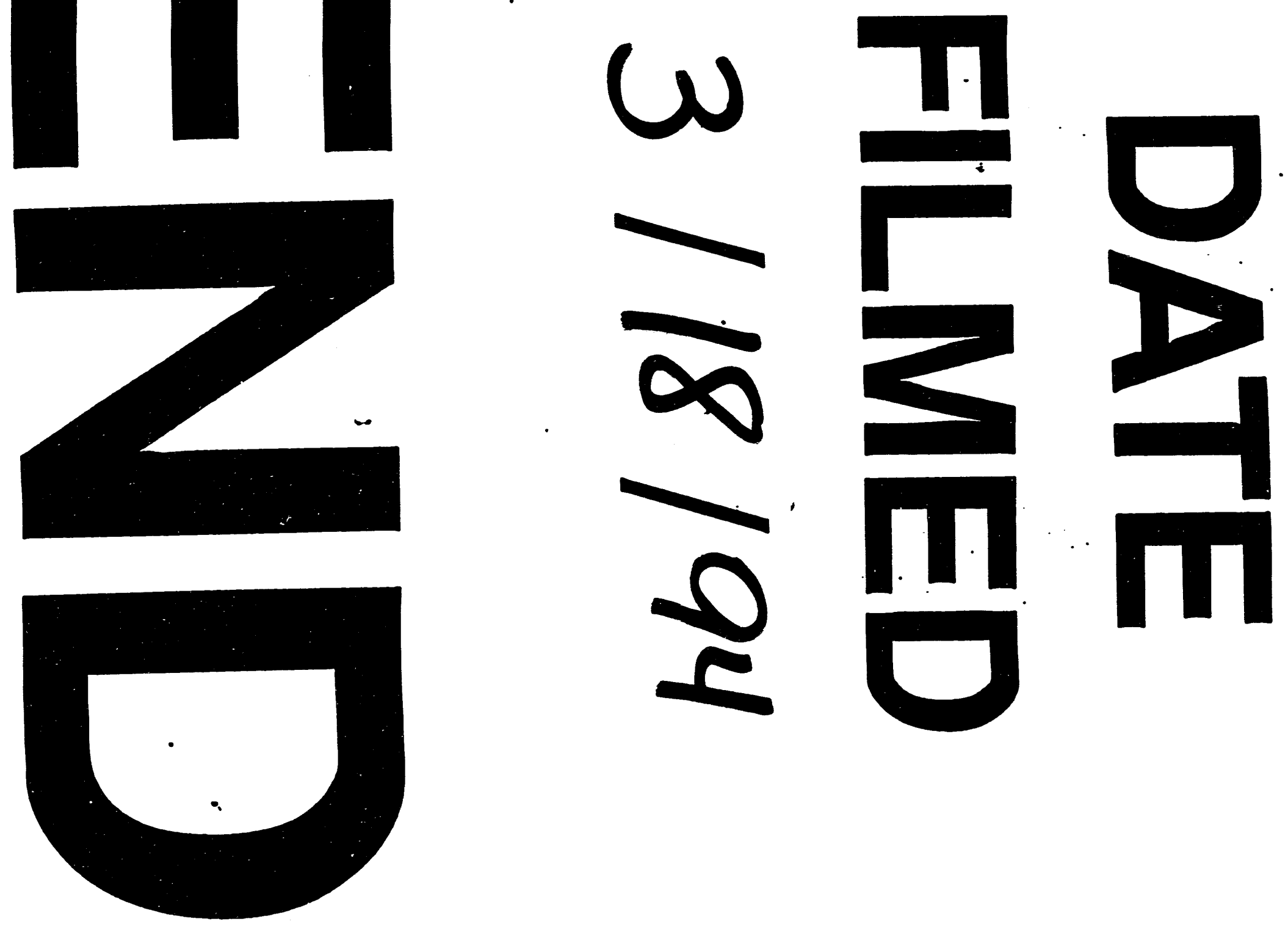


$$
\mathrm{C}_{\mathrm{C}} \mathrm{C}
$$

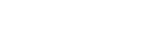

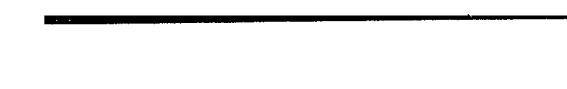

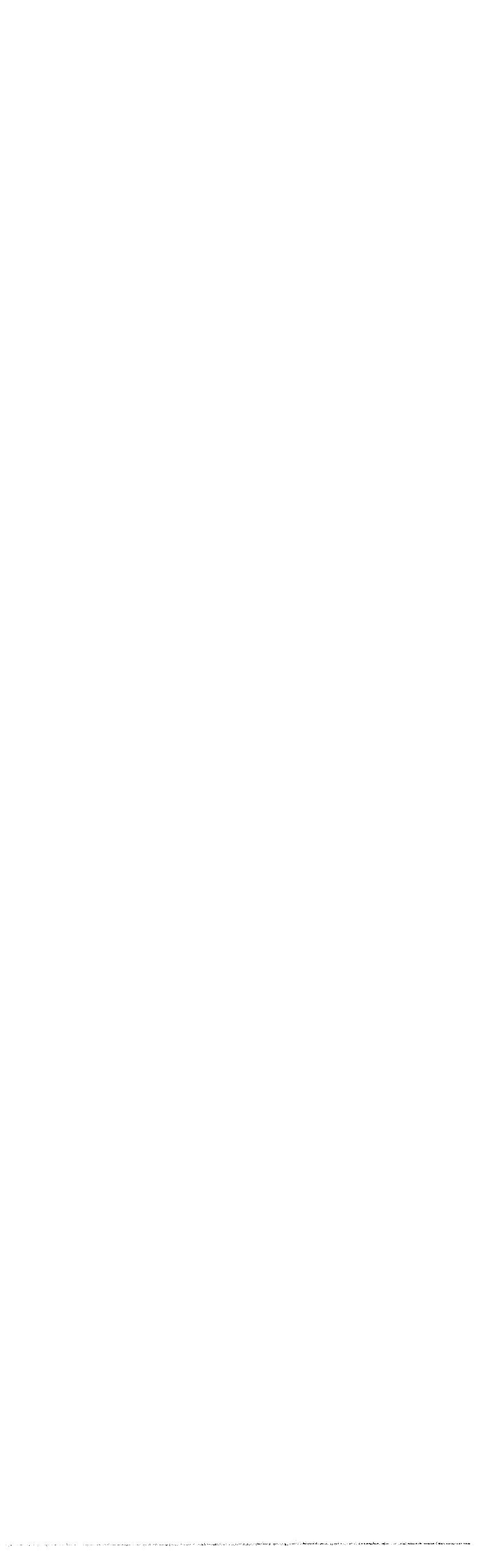

